\title{
The determination of ubiquinone profiles by reversed-phase high- performance thin-layer chromatography as an aid to the speciation of Legionellaceae
}

\author{
K. MitChell* and R. J. FALlon \\ Department of Laboratory Medicine, Ruchill Hospital, Bilsland Drive, Glasgow G20 9NB, UK
}

(Received 2 January 1990; revised 28 June 1990; accepted 5 July 1990)

\begin{abstract}
Ubiquinones extracted from 24 strains of Legionella pneumophila (including the type strains of serogroups 1-14 and one proposed new serogroup) and from 44 strains of other Legionella species (including 28 type strains and strains of five proposed new species) were analysed by reversed-phase thin-layer chromatography. Ubiquinone profiles as determined by this method were reproducible, both qualitatively and semi-quantitatively, and provided information to aid in the identification of species of Legionella. Results of ubiquinone profiles determined by different laboratories were compared. Some quantitative differences in results between laboratories were observed, which may be due to different analytical procedures. For this reason laboratories should establish their own library of ubiquinone profiles. New information is presented on the ubiquinone profiles of seven Legionella species: $L$. birminghamensis, $L$. brunensis, $L$. cincinnatiensis, $L$. moravica, $L$. quinlivanii, $L$. tucsonensis and proposed new species no. 1347, ' $L$. worsleiensis'.
\end{abstract}

\section{Introduction}

Ubiquinones and menaquinones are constituents of bacterial plasma membranes, where they play an important role in respiratory electron transport. Structural differences in these respiratory quinones have been used as a basis for bacterial classification (Collins et al., 1977). The Legionellaceae possess an unusual pattern of respiratory ubiquinones where the number of isoprene units $(Q)$ on the benzoquinone ring ranges between 9 and 15. In other families of bacteria, the chain length ranges from 7 to 10 units (Gilbart \& Collins, 1985). These differences in hydrocarbon chain length allow a mixture of ubiquinones to be separated (Collins \& Jones, 1981).

Using reversed-phase thin-layer chromatography (RPTLC) and mass spectrometry, Karr et al. (1982) identified Q-9 to Q-13 in a range of Legionella species. These observations were extended by Moss et al. (1983), who detected Q-14, as well as Q-13, in L. feeleii WO-44C by both RPTLC and reversed-phase high-performance liquid chromatography; these ubiquinones were confirmed by mass spectrometry. Collins \& Gilbart (1983) published quantitative ubiquinone profiles, which included Q-14 and Q-15, of twelve Legionella test strains

\footnotetext{
Abbreviations: RPTLC, reversed-phase thin-layer chromatography; SG, serogroup.
}

determined by high-performance liquid chromatography (HPLC). Comprehensive information on ubiquinones found in 23 Legionella species analysed by HPLC has been published by Lambert \& Moss (1989).

In our laboratory HPLC is not available and a library of ubiquinone profiles of all known Legionella species has been established by RPTLC. This method is convenient in that it does not require sophisticated and expensive equipment, is experimentally undemanding and gives highly reproducible results. It is therefore a simple method which could be employed by clinical laboratories. Here we describe the method and report ubiquinone profiles for seven species of Legionella which have not been investigated previously in this respect.

\section{Methods}

Bacterial strains and cultural conditions. Strains of Legionella (Table 1) were grown on ACES-buffered charcoal yeast extract agar (BCYE) (Edelstein, 1981) for $48 \mathrm{~h}$ at $37 \pm 1^{\circ} \mathrm{C}$ in air in sealed jars. Two strains were also grown on Oxoid BCYE (code CM 655 with Legionella growth supplement SR 110) and incubated as described for BCYE.

Direct extraction of ubiquinones. A modification of the procedure of Krivankova \& Dadak (1980) was used, as described by Karr et al. (1982). Briefly, fresh whole cells scraped from the surface of two Petri dishes $(100 \times 15 \mathrm{~mm})$, taking care to avoid picking up medium fragments, were suspended in $3 \mathrm{ml}$ methanol/n-hexane $(3: 2, \mathrm{v} / \mathrm{v})$ in a glass container. This suspension was vortex-mixed for $1 \mathrm{~min}$ and then 
Table 1. Legionella strains investigated

\begin{tabular}{|c|c|c|c|}
\hline Species & Serogroup & Strain no. & Source $†$ \\
\hline L. anisa & - & $\mathrm{CH}-47-\mathrm{C}-1$ & $\mathrm{CDC}$ \\
\hline L. birminghamensis & - & 1407-AL-H & CDC \\
\hline L. bozemanii & 1 & WIGA & $\mathrm{CDC}$ \\
\hline L. bozemanii & 2 & Toronto-3 & CDC \\
\hline L. brunensis & - & 444-1 & CDC \\
\hline L. cherrii & - & ORW & CDC \\
\hline L. cincinnatiensis & - & 70-OH-H & CDC \\
\hline L. dumoffii & - & TEX-KL & CDC \\
\hline L. erythra & - & SE-32A-C8 & $\mathrm{CDC}$ \\
\hline L. feeleii & 1 & WO-44-C3 & CDC \\
\hline L. feeleii & 2 & 691-W1-H & $\mathrm{CDC}$ \\
\hline 'L. geestiae'* & - & 1308 & CAMR \\
\hline L. gormanii & - & LS-13 & $\mathrm{CDC}$ \\
\hline L. gratiana & - & ATCC 49413 & Lyon \\
\hline L. hackeliae & 1 & Lansing-2 & CDC \\
\hline L. hackeliae & 2 & 798-PA-H & CDC \\
\hline L. israelensis & - & Bercovier-4 & CDC \\
\hline L. jamestowniensis & - & JA-26-G1-E2 & CDC \\
\hline L. jordanis & - & BL-540 & CDC \\
\hline 'L. londoniensis" & - & 1224 & CAMR \\
\hline L. longbeachae & 1 & Longbeach-4 & CDC \\
\hline L. longbeachae & 2 & Tucker-1 & CDC \\
\hline L. macheachernii & - & PX-1-G2-E2 & $\mathrm{CDC}$ \\
\hline L. micdadei & - & TATLOCK & $\mathrm{CDC}$ \\
\hline L. moravica & - & $316-36$ & CAMR \\
\hline 'L. nautarum'* & - & 1447 & CAMR \\
\hline L. oakridgensis & - & OR-10 & $\mathrm{CDC}$ \\
\hline L. parisiensis & - & PF-209C-C2 & CDC \\
\hline L. pneumophila & 1 (Camperdown) & NCTC 12098 & \\
\hline L. pneumophila & 1 (Knoxville-1) & & $\mathrm{CDC}$ \\
\hline L. pneumophila & 1 (Olda 1a) & 2129 & CAMR \\
\hline L. pneumophila & 1 (Olda $1 c)$ & 2143 & CAMR \\
\hline L. pneumophila & 1 (Philadelphia-1) & & $\mathrm{CDC}$ \\
\hline L. pneumophila & 1 (Pontiac-1) & NCTC 11191 & \\
\hline L. pneumophila & 1 (Hastings strain) & & Nottingham PHL \\
\hline L. pneumophila & 2 & Togus-1 & $\mathrm{CDC}$ \\
\hline L. pneumophila & 3 & Bloomington-2 & $\mathrm{CDC}$ \\
\hline
\end{tabular}

$8 \mathrm{ml}$-hexane was added and the mixing procedure repeated. Centrifugation at $120 \mathrm{~g}$ for $10 \mathrm{~min}$ assisted partition of the solvents, and the top layer of $n$-hexane was removed without disturbing any cellular debris at the methanol/n-hexane interface. The aqueous phase was re-extracted with a further $8 \mathrm{ml}$-hexane. The combined hexane extracts were dried in vacuo in foil-covered vials to avoid photodegradation.

RPTLC analysis of ubiquinones. Cellular extracts $(30-50 \mu 1)$ were spotted onto $20 \times 20 \mathrm{~cm}$ octadecylsilane-bonded reversed-phase $\mathrm{KC}_{18}$ F TLC plates (Whatman), ensuring similar quantities of extracted material between samples, together with $10 \mu \mathrm{l}$ of ubiquinone standards Q-6 and Q-10 (Sigma), each at concentrations of $0.5 \mathrm{mg} \mathrm{ml}^{-1}$. Plates were developed in acetone/water $(19: 1, \mathrm{v} / \mathrm{v})$ until the solvent had risen to within $2-3 \mathrm{~cm}$ of the top. Then, after air drying, plates were sprayed with $10 \%(\mathrm{w} / \mathrm{v})$ phosphomolybdic acid (Sigma) from a distance of 20 $25 \mathrm{~cm}$ followed by heating at $160^{\circ} \mathrm{C}$ for $30-50 \mathrm{~s}$, when blue-green spots developed on a yellow background. In addition to ubiquinones, other hexane-soluble materials, e.g. phospholipids, were observed on the RPTLC plates but these were well separated from ubiquinones and did not interfere with their interpretation.

Relative mobility ( $R_{\mathrm{F}}$ values) were calculated by dividing the distance travelled by each ubiquinone individually by the distance travelled by the solvent. This was done for the two commercial ubiquinone standards, as well as ubiquinones extracted from $L$. pneumophila SG 1 (Knoxville-1), used as a control for the extraction method. These $R_{\mathrm{F}}$ values were plotted against the number of isoprenoid units (Q) (see Fig. 1). This allowed tentative identification of ubiquinones extracted from other legionellae.

Saponification of ubiquinones. A modification of the procedure of Abe et al. (1978), described by Karr et al. (1982), was employed. Fresh whole cells $(0.4 \mathrm{~g}$ wet weight) were scraped from two BCYE agar plates; a suspension was made in $3 \mathrm{ml} \mathrm{1 \%}(\mathrm{w} / \mathrm{v})$ pyrogallol in methanol and this was transferred to a $10 \mathrm{ml}$ Quickfit flask. To this, $0.2 \mathrm{ml} 50 \%$ aqueous $\mathrm{KOH}$ was added. The flask was attached to a reflux condenser $(260 \mathrm{~mm})$ and the mixture refluxed for $10 \mathrm{~min}$ at $100^{\circ} \mathrm{C}$ followed by immediate cooling by placing the flask under running tap water. A $1 \mathrm{ml}$ quantity of distilled water and $5 \mathrm{ml} \mathrm{n}$-hexane were added and the mixture shaken vigorously for $5 \mathrm{~min}$ and then centrifuged at $120 \mathrm{~g}$ for $10 \mathrm{~min}$. The hexane layer was removed and the aqueous phase was reextracted with an additional $5 \mathrm{ml} \mathrm{n}$-hexane. The hexane layers were combined and evaporated to dryness in vacuo and the resulting residue dissolved in ethyl acetate for RPTLC.

Mass spectrometry. Some of the extracts used in this work were examined at the PHLS Centre for Applied Microbiological Research, Porton Down, Salisbury, UK, and the presence of ubiquinones in these extracts was confirmed by mass spectrometry using a Kratos MS 80 RFA mass spectrometer fitted with an Ion-Tech BNF 11 fast-atom gun 
Table 1 (continued)

\begin{tabular}{|c|c|c|c|}
\hline Species & Serogroup & Strain no. & Source $†$ \\
\hline L. pneumophila & $4 \zeta$ Subsp. & Los-Angeles-1 & CDC \\
\hline L. pneumophila & $5 \int$ fraseri & Dallas-1E & $\mathrm{CDC}$ \\
\hline L. pneumophila & 5 Subsn & MICU-B & Columbia \\
\hline L. pneumophila & $5\}^{\text {Subsp. }}$ & U7W & Columbia \\
\hline L. pneumophila & 5] pascullel & U8W & Columbia \\
\hline L. pneumophila & 6 & Oxford-1 & $\mathrm{CDC}$ \\
\hline L. pneumophila & 7 & Chicago-8 & CDC \\
\hline L. pneumophila & 8 & Concord-3 & $\mathrm{CDC}$ \\
\hline L. pneumophila & 9 & IN-23-G1-C2 & $\mathrm{CDC}$ \\
\hline L. pneumophila & 10 & Leiden-1 & CDC \\
\hline L. pneumophila & 11 & 797-PA-H & $\mathrm{CDC}$ \\
\hline L. pneumophila & 12 & 570-CO-H & $\mathrm{CDC}$ \\
\hline L. pneumophila & 13 & Seattle-1 & CDC \\
\hline L. pneumophila & 14 & 1169-MN-H & CDC \\
\hline L. pneumophila* & Lansing 3 & Subsp. fraseri & $\mathrm{CDC}$ \\
\hline 'L. quateriensis'" & - & 1335 & CAMR \\
\hline L. quinlivanii & - & 1442-AUS-E & $\mathrm{CDC}$ \\
\hline L. quinlivanii & - & 1448-AUS-E & CDC \\
\hline L. quinlivanii & - & 1449-AUS-E & CDC \\
\hline L. quinlivanii & - & 1450-AUS-E & CDC \\
\hline L. quinlivanii & - & 1451-AUS-E & $\mathrm{CDC}$ \\
\hline L. quinlivanii & - & 1452-AUS-E & CDC \\
\hline L. quinlivanii & - & 2359-AUS-E & CDC \\
\hline L. rubrilucens & - & 1267 & CAMR \\
\hline L. sainthelensi & - & Mt St Helens-4 & CDC \\
\hline L. santicrucis & - & SC-63-C7 & $\mathrm{CDC}$ \\
\hline L. spiritensis & - & Mt St Helens-9 & CDC \\
\hline L. steigerwaltii & - & SC-18-CD & $\mathrm{CDC}$ \\
\hline L. tucsonensis & - & 1087-A2-H & $\mathrm{CDC}$ \\
\hline L. wadsworthii & - & $81-716 \mathrm{~A}$ & CAMR \\
\hline 'L. worsleiensis' & - & 1347 & CAMR \\
\hline
\end{tabular}

* Proposed new species or un-numbered new serogroup.

$\dagger$ Cultures were obtained from: the culture collection of the Centers for Disease Control (CDC), Atlanta, Georgia, USA; PHLS CAMR, Porton Down, Salisbury, UK; Dr N. Bornstein, Centre National de Reference des Legionelloses, Lyon, France; Dr A. Brown, Wm Jennings Bryon Dorn Veterans' Hospital, Columbia, USA; and Dr A. D. Macrae, PHL Nottingham, UK.

and a Kratos fast-atom bombardment (FAB) source. This method of negative-ion fast-atom bombardment has not previously been applied to the identification of ubiquinones but provides valuable data $(R$. Wait, personal communication).

\section{Results and Discussion}

Fig. 1 shows the relationship between the number of isoprenoid units and the relative mobility $\left(R_{\mathrm{F}}\right)$ of ubiquinones on RPTLC plates.

Some plates were examined under UV light $(254 \mathrm{~nm})$ and areas of UV absorption representing ubiquinones were observed. Although absorption patterns were seen, it was difficult to estimate in what quantities these ubiquinones were present. The phosphomolybdate spray reagent, although not specific for ubiquinones, did yield more detail in the areas where ubiquinones were expected to be resolved. This greater sensitivity and the resultant semi-permanent RPTLC plate made results easier to read and record and this outweighed the

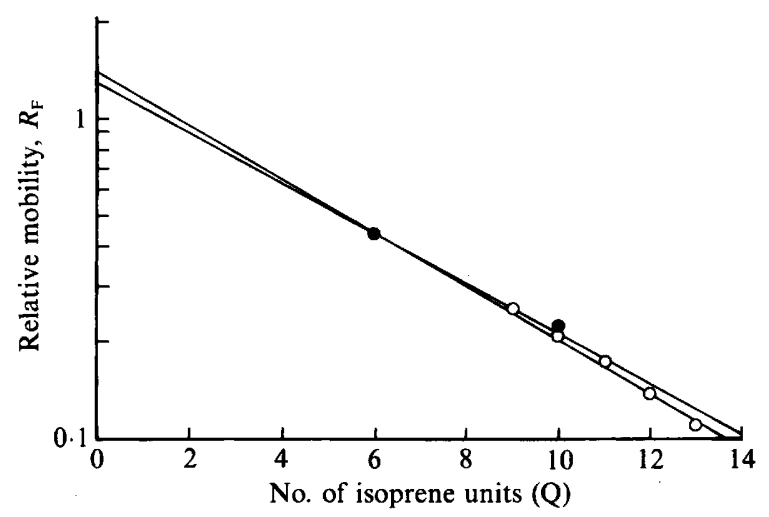

Fig. 1. Plot of the $R_{\mathrm{F}}$ values on RPTLC (log scale) of ubiquinones extracted from $L$. pneumophila SG 1 (Knoxville-1) $(O)$ and of purified standards, Q-6 and Q-10 (Sigma) (O) against the number of isoprenoid units $(Q)$.

disadvantage of other unsaturated lipids being shown up by the phosphomolybdate on the plate.

The method used for saponification of the extracts removed many of the other lipids observed on the 
Table 2. Ubiquinone profiles of 35 Legionella species as determined semi-quantitatively by $R P T L C$ and grouped according to the ubiquinone observed to be of the highest relative concentration

The numbers refer to visual estimates of the relative amounts of ubiquinones, with the major components designated as 4,2 (half the amount of 4 ), $3(>2$ but $<4$ ), and 1 (half the amount of 2 ). tr, trace amounts; -, not detected. Predominant ubiquinone: group A, Q-13; group B, Q-12; group C, Q11; group D, Q-10; group E, species with two or more ubiquinones present in equally high concentration.

\begin{tabular}{|c|c|c|c|c|c|c|c|}
\hline \multirow[b]{2}{*}{ Species } & \multicolumn{6}{|c|}{ Ubiquinone content } & \multirow[b]{2}{*}{ Group } \\
\hline & Q-9 & Q-10 & Q-11 & Q-12 & Q-13 & Q-14 & \\
\hline L. anisa & $\operatorname{tr}-1$ & 4 & 2 & 3 & 2 & - & D \\
\hline L. birminghamensis & 1 & $2-3$ & 4 & 2 & 1 & - & C \\
\hline L. bozemanii SG1 and 2 & - & $3-4$ & 2 & 4 & $1-2$ & - & $\mathrm{E}$ \\
\hline L. brunensis & tr & 2 & 3 & 2 & 4 & tr-1 & $\overline{\mathbf{A}}$ \\
\hline L. cherrii & $\operatorname{tr}-1$ & 4 & 2 & 4 & 2 & - & $\mathrm{E}$ \\
\hline L. cincinnatiensis & - & 4 & 2 & 2 & 2 & - & D \\
\hline L. dumoffii & 1 & 3 & 3 & 4 & 2 & - & $\bar{B}$ \\
\hline L. erythra & 1 & $3-4$ & 3 & $2-3$ & $2-3$ & $\operatorname{tr}$ & D \\
\hline L. feeleii SG1 and 2 & - & 2 & 1 & 1 & 4 & $3-4$ & $\mathbf{E}$ \\
\hline 'L. geestiae' (1308) & 1 & $2-3$ & 1 & $i$ & 4 & 4 & $\mathrm{E}$ \\
\hline L. gormanii & - & $2-3$ & 2 & 4 & $1-2$ & - & B \\
\hline L. gratiana & 1 & 4 & 2 & 3 & $\operatorname{tr}$ & - & $\mathrm{D}$ \\
\hline L. hackeliae SG1 and 2 & - & $2-3$ & $2-3$ & 2 & 4 & 1 & $\mathrm{~A}$ \\
\hline L. israelensis & $\operatorname{tr}$ & 3 & 3 & 4 & 4 & $\operatorname{tr}$ & $\mathrm{E}$ \\
\hline L. jamestowniensis & $\mathrm{tr}$ & 4 & 3 & $2-3$ & $2-3$ & - & $\mathrm{D}$ \\
\hline L. jordanis & - & 3 & 2 & 3 & 4 & 1 & $\hat{A}$ \\
\hline 'L. londoniensis' (1224) & 1 & 3 & 2 & $1-2$ & 4 & $\operatorname{tr}$ & A \\
\hline L. longbeachae $\mathrm{SGl}$ and 2 & 1 & 3 & 2 & $3-4$ & 1 & - & E \\
\hline L. maceachernii & 1 & 4 & $1-2$ & $1-2$ & 4 & $1-2$ & $\mathbf{E}$ \\
\hline L. micdadei & 1 & 4 & 2 & 2 & 4 & - & $\mathbf{E}$ \\
\hline L. moravica & $i$ & 2 & 1 & 1 & 4 & 1 & $\mathrm{~A}$ \\
\hline 'L. nautarum' (1447) & - & 1 & 1 & 4 & 2 & - & B \\
\hline L. oakridgensis & - & 4 & $1-2$ & 1 & 2 & - & D \\
\hline L. parisiensis & - & $3-4$ & $3-4$ & 4 & 1 & _- & $\mathbf{E}$ \\
\hline L. pneumophila SG1-14 & - & 2 & 1 & 4 & $2-3$ & - & B \\
\hline 'L. quateriensis' (1335) & 1 & 2 & 3 & 2 & 4 & $\operatorname{tr}-1$ & A \\
\hline L. quinlivanii & 1 & 2 & 2 & 4 & $1-2$ & - & B \\
\hline L. rubrilucens & - & 2 & 2 & 4 & 1 & - & B \\
\hline L. sainthelensi & - & $3-4$ & 3 & $3-4$ & 2 & _- & $\mathbf{E}$ \\
\hline L. santicrucis & 1 & 4 & 3 & 3 & $2-3$ & - & D \\
\hline L. spiritensis & - & 1 & $1-2$ & 1 & 4 & $\mathrm{tr}$ & A \\
\hline L. steigerwaltii & - & 2 & 2 & 4 & 1 & - & B \\
\hline L. tucsonensis & 1 & 3 & 3 & 4 & 2 & - & B \\
\hline L. wadsworthii & - & 4 & $2-3$ & $2-3$ & 1 & - & D \\
\hline 'L. worsleiensis' (1347) & - & $1-2$ & 1 & 3 & 4 & _- & A \\
\hline
\end{tabular}

RPTLC plate beyond the area where ubiquinones were resolved. Results obtained by this method were compared, for 10 strains, with direct extraction. Only one strain (L. maceachernii) showed any difference, less Q-10 being found in the saponified extract than in the direct extraction. The direct extraction procedure took less time and thus was chosen to compile the library of ubiquinone profiles of the Legionellaceae.

Table 2 was compiled from the results of ubiquinone analyses by RPTLC of 35 Legionella species. A semiquantitative assessment of the ubiquinones was achieved subjectively, the density of spots being assigned a numerical value on the basis of intensity observed on the RPTLC plate. All analyses by RPTLC were repeated at least twice to check ubiquinone profile stability, with identical results being obtained for each Legionella strain tested. All strains analysed contained ubiquinones with $10-13$ isoprenoid units in the side chains. Twelve species (fourteen strains) had trace to small amounts of Q-14, but L. feeleii SG 1 and 2, and proposed new species no. 1308, 'L. geestiae', had substantial amounts of this ubiquinone. Q-9 was found in 19 of the species (27 strains) analysed, including $L$. longbeachae SG 1 and 2 , and the seven strains of $L$. quinlivanii (Table 2). However, Q-9 was more difficult to detect on a RPTLC plate since it ran close to Q-10 and other lipid components. Visually, the other ubiquinones were more easily distinguished.

No qualitative or quantitative differences were detec- 


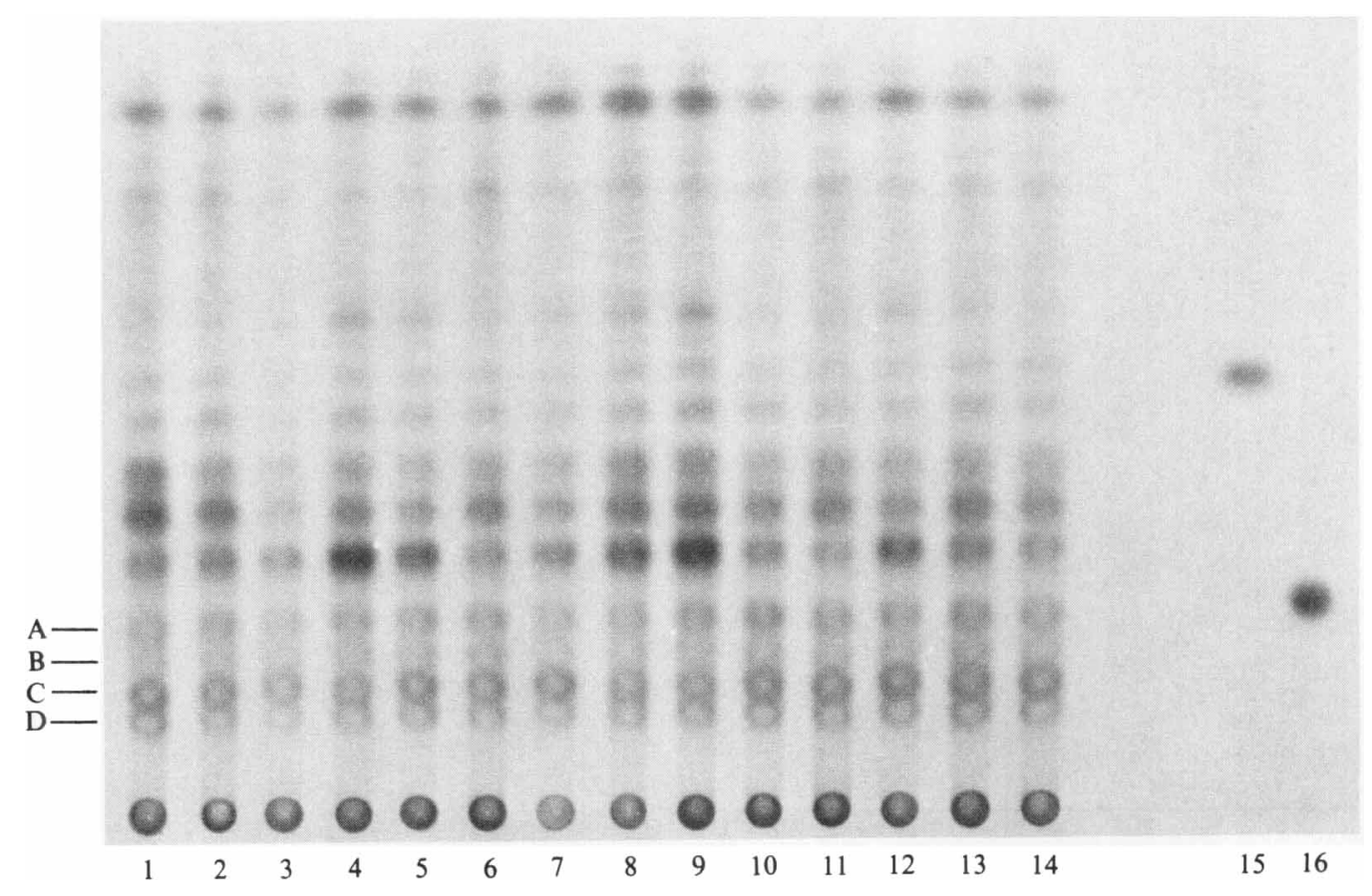

Fig. 2. RPTLC plate of ubiquinones (A, Q-10; B, Q-11; C, Q-12; D, Q-13) extracted from fresh whole cells of $L$. pneumophila species: lane 1, L. pn. SG 1 (Knoxville-1); lane 2, L.pn. SG 2; lane 3, L.pn. SG 3; lane 4, L.pn. SG 4; lane 5, L.pn. SG 5 (Dallas 1E); lane 6, L.pn. SG 6; lane 7, L.pn. SG 7; lane 8, L.pn. SG 8; lane 9, L.pn. SG 9; lane 10, L.pn. SG 10; lane 11, L.pn. SG 11; lane 12, L.pn. SG 12; lane 13, L.pn. SG 13; lane 14, L.pn. SG 14; lane 15, Q-6 standard (Sigma); lane 16, Q-10 standard (Sigma).

table in the ubiquinone profiles of the L. pneumophila strains analysed (Fig. 2), but many differences, both qualitative and quantitative, were evident when profiles of some of the other Legionella species were examined (Fig. 3).

The ubiquinone profiles of the 68 Legionella strains allowed each species to be placed in one of five groups, designated A-E (Table 2). All the strains of $L$. pneumophila, including L. pneumophila subsp. pneumophila (DNA group 1), L. pneumophila subsp. fraseri (DNA group 2) (Fig. 2) and L. pneumophila subsp. pascullei (Brenner et al., 1988), gave ubiquinone profiles which were indistinguishable. These were assigned to group B (Table 2) as Q-12 was present in the highest relative quantity. Groups A, C, and D contained species for which the ubiquinone with the highest relative concentration was Q-13, Q-11 and Q-10, respectively. Group $E$ contained species where no one ubiquinone predominated, i.e. two or more ubiquinones were observed in the highest quantity.

This system of grouping legionellae according to their predominant ubiquinone is simple both in terms of definition of a group and of allocation of strains to a group. [It should not be confused with that of Lambert \& Moss (1989), where 23 Legionella species were placed in groups according to their ubiquinone profiles as analysed by HPLC.] The five groups dividing the Legionellaceae are distributed as follows: group A, eight species (23\%); group B, eight species (23\%); group C, one species ( $3 \%$ ); group $\mathrm{D}$, eight species $(23 \%)$; and group $\mathrm{E}$, ten species $(28 \%)$. Legionella species assigned to any one group may be further differentiated if necessary on the relative amounts of ubiquinones other than that which is dominant.

Ubiquinone profiles analysed by RPTLC may also be used to discriminate between the blue/white autofluorescent and the red autofluorescent species where these may be difficult to identify serologically. Of the eight currently described blue/white autofluorescent species, $L$. dumoffii, L. gormanii, $L$. steigerwaltii and $L$. tucsonensis were designated members of group $B$ by their ubiquinone profiles and could be differentiated from $L$. bozemanii, $L$. cherrii and $L$. parisiensis of group $\mathrm{E}$ and $L$. anisa of group D. The two red autofluorescent species $L$. erythra and $L$. rubrilucens could also be differentiated, as they were assigned to groups $\mathrm{D}$ and $\mathrm{B}$ respectively.

The reproducibility of ubiquinone profiles was investigated in two legionellae, a human pathogenic strain, $L$. pneumophila SG 1 (Knoxville-1 strain), and an environmental strain, ' $L$. geestiae'. Profiles were constant whether cultures were incubated for $48,96,192$ or $240 \mathrm{~h}$ at $37^{\circ} \mathrm{C}$ and also whether grown on Oxoid or in-house BCYE.

RPTLC has been used to analyse strains other than the stock strains shown in Table 2. Six legionellae isolated from the environment reacted with unabsorbed $L$. 


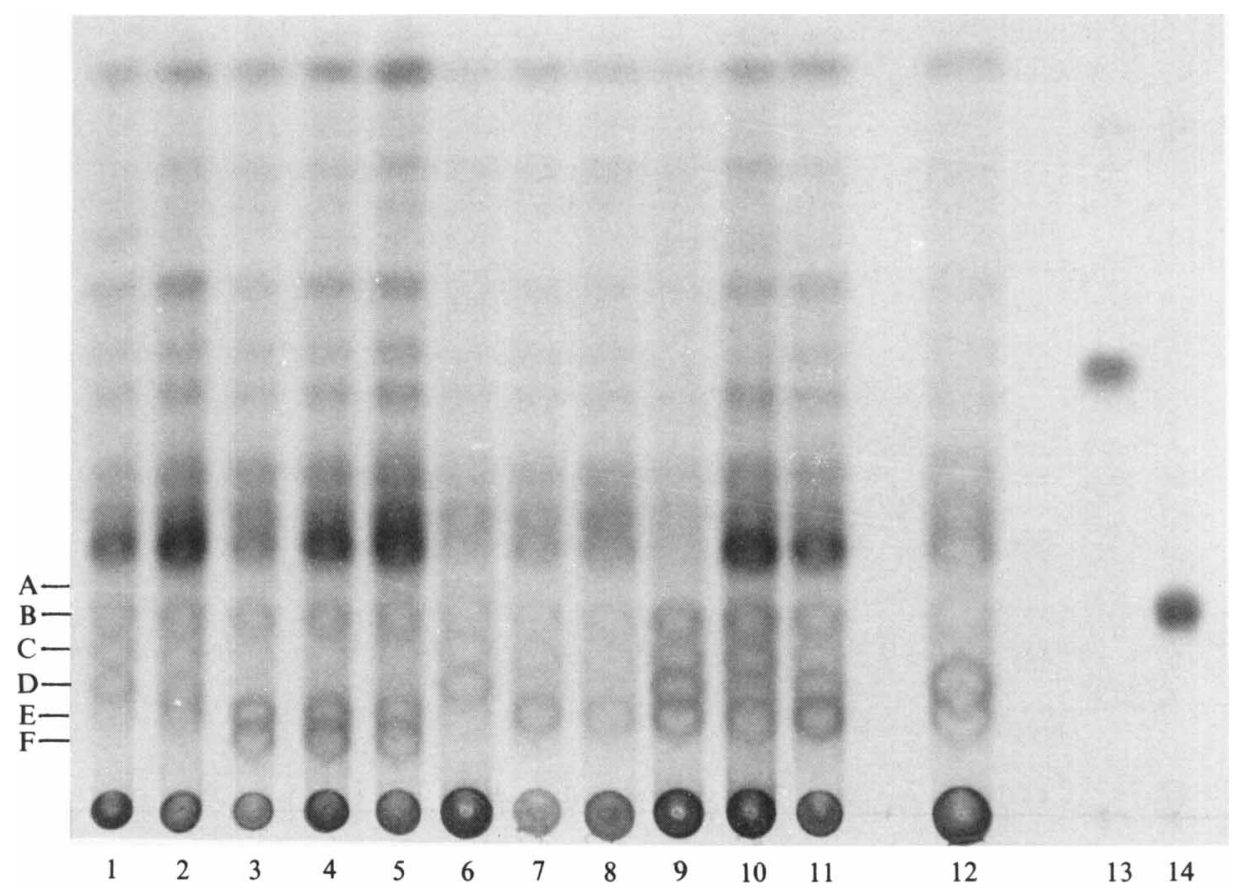

Fig. 3. RPTLC plate showing some of the similarities and differences of ubiquinone profiles (summarized in Table 2) amongst twelve strains of legionellae. Lane 1, L. dumoffii; lane 2, L. erythra; lane 3, L. feeleii SG 1; lane 4, L. feeleii SG 2; lane 5, 'L. geestiae'; lane 6, L. gormanii; lane 7, L. hackeliae SG 1 ; lane $8, L$. hackeliae SG 2; lane 9, L. israelensis; lane 10, L. jamestowniensis; lane 11, L. jordanis; lane 12, L. pneumophila SG 1 (Knoxville-1) control; lane 13, Q-6 standard (Sigma); lane 14, Q-10 standard (Sigma). Ubiquinones are: A, Q-9; B, Q-10; C, Q-11; D, Q-12; E, Q-13; F, Q-14.

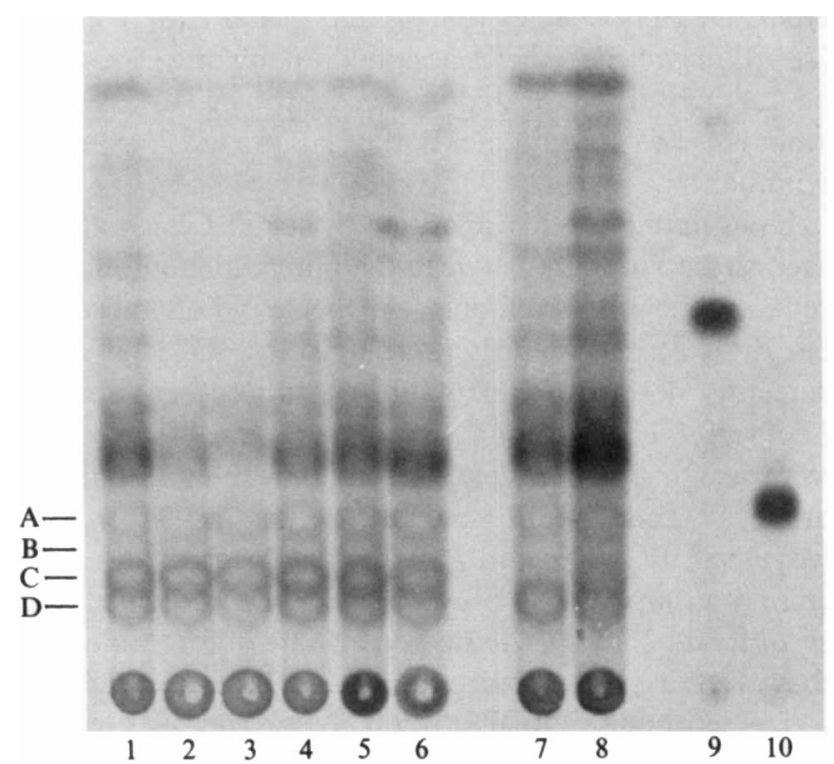

Fig. 4. RPTLC plate showing ubiquinone profiles from six legionellae isolated from environmental samples (lanes 1-6) and two type strains, L. hackeliae SG 1 (lane 7) and L. pneumophila SG 1 (Knoxville-1) (lane 8). Lane 9, Q-6 standard (Sigma); lane 10, Q-10 standard (Sigma). Ubiquinones are: A, Q-10, B, Q-11; C, Q-12; D, Q-13.

hackeliae SG1 guinea-pig antiserum (IFA titre $=512$, positive control with the homologous organism, 1024). Their ubiquinone profiles (Fig. 4), matched closely those of $L$. pneumophila and not those of $L$. hackeliae. Further studies of fatty acids by GLC supported these findings and the organisms were subsequently identified using serogroup-specific rabbit antisera to be $L$. pneumophila SG 1 (three strains), SG6 (two strains) and SG12 (one strain).

Another strain of Legionella (ML-76) was analysed for its ubiquinone profile and found to be indistinguishable from $L$. spiritensis, agreeing with the findings of Harrison et al. (1988). Also our findings with L. gratiana, in which Q-10 is the predominant ubiquinone, agree with those of Bornstein et al. (1989), which were derived using HPLC.

These results suggest that ubiquinone profiles of the Legionellaceae as determined by RPTLC are a stable and constant feature which can be used to aid in species identification.

Our results for 10 Legionella species are compared with those of two other groups, who used HPLC, in Table 3. One group (Collins \& Gilbart 1983; Gilbart \& Collins, 1985) expressed their HPLC peaks of ubiquinones as percentages of the total ubiquinone content. The other group (Lambert \& Moss, 1989) reported their ubiquinone data based on a visually estimated scale of 1-4 dependent on the relative concentrations of ubiquinones observed. As the method of presentation between these workers differed, comparison of results was achieved by applying the simple method of grouping as described in this paper. Where only the predominant ubiquinones were used to group the legionellae, the method of RPTLC compared 
Table 3. A summary of the groups into which 10 Legionella species fall when analysed by three groups of workers using HPLC or RPTLC to determine ubiquinone profiles

Group A, Q-13 predominates; group B, Q-12 predominates; group C, Q-11 predominates; group $\mathrm{D}, \mathrm{Q}-10$ predominates; group $\mathrm{E}$, more than one ubiquinone predominates in the overall profile of a species.

\begin{tabular}{lccc}
\hline \hline & \multicolumn{3}{c}{ Groups obtained with results of: } \\
\cline { 2 - 4 } \multicolumn{1}{c}{ Species } & $\begin{array}{c}\text { Collins \& Gilbart } \\
(1983,1985) \\
\text { (HPLC) }\end{array}$ & $\begin{array}{c}\text { Lambert \& Moss } \\
(1989) \\
\text { (HPLC) }\end{array}$ & $\begin{array}{c}\text { This paper } \\
\text { (RPTLC) }\end{array}$ \\
\hline L. bozemanii & $\mathrm{E}$ & $\mathrm{E}$ & $\mathrm{E}$ \\
L. dumoffi & $\mathrm{B}$ & $\mathrm{E}$ & $\mathrm{B}$ \\
L. gormanii & $\mathrm{B}$ & $\mathrm{E}$ & $\mathrm{B}$ \\
L. jordanis & $\mathrm{A}$ & $\mathrm{E}$ & $\mathrm{A}$ \\
L. longbeachae & $\mathrm{B}$ & $\mathrm{A}$ & $\mathrm{E}$ \\
L. micdadei & $\mathrm{A}$ & $\mathrm{D}$ & $\mathrm{A}$ \\
L. oakridgensis & $\mathrm{D}$ & $\mathrm{B}$ & D \\
L. pneumophila & $\mathrm{B}$ & $\mathrm{E}$ & $\mathrm{B}$ \\
L. sainthelensi & $\mathrm{B}$ & $\mathrm{D}$ & $\mathrm{E}$ \\
L. wadsworthii & $\mathrm{D}$ & & $\mathrm{D}$ \\
\hline \hline
\end{tabular}

well with the results produced by HPLC. However, some differences were observed between the quantities of ubiquinones of some legionellae both between RPTLC and HPLC results and also between HPLC results where these had been carried out in different laboratories. We observed greater amounts of Q-10 in three of the 10 species in Table 3 L. jordanis, $L$. longbeachae and $L$. micdadei) than reported by other workers. The reason for this is unclear but the possibility that it could be due to a lipid component of $R_{\mathrm{F}}$ value similar to Q-10 warrants further investigation, including mass spectrometry. Differences between analytical methods may account for other minor differences noted between laboratories.

RPTLC, like HPLC, when employed to analyse the composition of ubiquinones cannot be used alone to give a definitive identification of a Legionella to species level, but is most useful when used in conjunction with serology, analysis of fatty acids by GLC, autofluorescence, DNA restriction fragment length polymorphisms (Harrison et al., 1988), and most definitively with DNA homology (Brenner et al., 1988).

We wish to express our sincere thanks to Mr R. Wait, PHLS CAMR, Porton Down, Salisbury, for mass spectrometry analyses and to Professor J. H. Freer, Department of Microbiology, University of Glasgow, for helpful discussion and for critical appraisal of this manuscript. This work was supported by the Scottish Home and Health Department under a grant for the New Developments in Health Care.

\section{References}

Abe, K., Ishibashi, M., Ohmae, M., Kawabe, K. \& Katsui, G. (1978). Determination of ubiquinone in serum and liver by high speed liquid chromatography. Journal of Nutritional Science and Vitaminology 24, 555-567.
Bornstein, N., Marmet, D., Surgot, M., Nowicki, M., Meugnier, H., Fleurette, J., Ageron, E., Grimont, F., Grimont, P. A. D., ThaCKER, W. L., BENSON, R. F. \& BRENNER, D. J. (1989). Legionella gratiana sp. nov. isolated from French spa water. Research in Microbiology 140, 541-552.

Brenner, D. J., Steigerwalt, A. G., Epple, P., Bibb, W. F., McKinney, R. M., Starnes, R. W., Colville, J. M., Selander, R. K., Edelstein, P. H. \& Moss, C. W. (1988). Legionella pneumophila serogroup Lansing 3 isolated from a patient with fatal pneumonia, and descriptions of $L$. pneumophila subsp. pneumophila subsp. nov., $L$. pneumophila subsp. fraseri subsp. nov., and $L$. pneumophila subsp. pascullei subsp. nov. Journal of Clinical Microbiology 26, 1695-1703.

Collins, M. D. \& Gilbart, J. (1983). New members of the coenzyme $\mathrm{Q}$ series from the Legionellaceae. FEMS Microbiology Letters 16, 251-255.

Collins, M. D. \& Jones, D. (1981). A note on the separation of natural mixtures of bacterial ubiquinones using reverse-phase partition thin layer chromatography and high performance chromatography. Journal of Applied Bacteriology 51, 129-134.

Collins, M. D., Pirouz, T., Goodfellow, M. \& Minnikin, D. E. (1977). Distribution of menaquinones in actinomycetes and corynebacteria. Journal of General Microbiology 100, 221-230.

EDELSTEIN, P. H. (1981). Improved semi-selective medium for isolation of Legionella pneumophila from contaminated clinical and environmental specimens. Journal of Clinical Microbiology 14, 298-303.

Gilbart, J. \& Collins, M. D. (1985). High performance liquid chromatographic analysis of ubiquinones from new Legionella species. FEMS Microbiology Letters 26, 77-82.

Harrison, T. G., Saunders, N. A., Doshi, N. \& Wait, R. (1988). Serological diversity within the species Legionella spiritensis. Journal of Applied Bacteriology 65, 425-431.

KARR, D. E., BIBB, W. F. \& Moss, C. W. (1982). Isoprenoid quinones of the genus Legionella. Journal of Clinical Microbiology 14, 1044-1048.

Krivanxova, L. \& Dadak, V. (1980). Semimicro extraction of ubiquinones and menaquinones from bacteria. Methods in Enzymo$\log y$ 67, 111-114.

LAMBERT, M. A. \& Moss, W. C.(1989). Cellular fatty acid compositions and isoprenoid quinone contents of 23 Legionella species. Journal of Clinical Microbiology 27, 465-473.

Moss, C. W., BibB, W. F., KARR, D. E., Guerrant, G. O. \& LamberT, M. A. (1983). Cellular fatty acid composition and ubiquinone content of Legionella feeleii sp. nov. Journal of Clinical Microbiology 18, 917-919. 